\title{
A Cognitive Analysis of Colors on Products and Brands
}

\author{
Jee-Ah Shin , Department of Business Administration, Sogang University, 35 Baekbeom-ro Mapo-gu Seoul, \\ 04107, South Korea. \\ *Jin-Hwa Kim, Department of Business Administration, Sogang University, 35 Baekbeom-ro Mapo-gu Seoul, \\ 04107, South Korea, jinhwakim@sogang.ac.kr \\ ${ }^{*}$ Corresponding Author
}

\begin{abstract}
The purpose of this study is to find perceptional differences on colors according to individual characteristics, products and company brands. This research collects surveys from participants on their cognition on colors alone with their statistical information. The independent variables are gender, age, favorite fruits, favorite foods, favorite subjects, favorite colors, favorite cellphone brands, favorite carriers, favorite car styles, and favorite car brands. The dependent variables are the associated products, the associated words, and the associated feelings of 6 colors: red, blue, green, yellow, white, and black. The results from decision tree analysis show the differences among the associated feeling of blue, the associated word of yellow, and the associated feeling of yellow. Firstly, most men feel 'calmness' and most women feel 'sadness' on blue. Secondly, people who like red thought that yellow is related to 'family', 'variety', or 'fun'. People who like black, green, or blue think of 'child', and ones who liked yellow or white think of 'fun' for yellow. Thirdly, people who like sedan or sports car feel 'happiness' and ones who like SUV, minivan, or coupe feel 'pleasure' for yellow. When comparing the associated products, the associated words, and the associated feelings of two brands (Samsung's Galaxy and Apple's iPhone) and two products (sedan and SUV), most results are similar but there are differences in several colors. In network graph of Samsung's Galaxy, Apple's iPhone, sedan, and SUV, the important words also appear somewhat differently. This study suggests applying the cognitive difference on colors by brands and products to the advertisement. Reflecting consumers' cognitions in the advertisement can be a comparative advantage to companies.
\end{abstract}

Keywords: Color Marketing, Cognitive Sciences, Decision Tree, Advertisements, Network Analysis

Received: 07.12.2020 $\quad$ Accepted: 16.01.2021 $\quad$ Published: 03.02.2021

\section{INTRODUCTION}

Color is a vital component in an advertisement. It can represent a certain brand or product. This can be appealing, but also be offensive. Therefore, it is important to specifically know which color evokes which emotion or association not to offend someone or discredit products [1].

Some brands remind people specific colors. It's easy to tell by reminiscent of the golden logo of 'McDonald' or the red symbol of 'Coca-Cola'. Using the brand color, they can show the unique personality of brand and engrave a clear impression. That's different from making marketing materials, building websites, or having content prettier. It's a way to change the way people view a company. Therefore, it is very important for companies to decide which color to use for the product image or advertisement. The image of a company that people have when they see the brand color is very diverse. Corporate identity is affected by many factors including the context of its color, the cultural differences, and the growth environment of the target audience. However, there are colors that are generally associated with certain emotions. There are general conceptual images of colors. Red is associated with passion, excitement, and anger. If a certain brand is lively, modern, or enjoyable, red may be the best match. Brands like 'CocaCola', 'Netflix', and 'Target' are typical. Yellow has a friendly, playful, and cheerful image. It can be often seen in the children's products because it gives a youthful and positive feeling. 'Kakao', a social media company, is well known for its yellow brand color. Green can convey various meanings from nature conservation or sustainability to a symbol of wealth. It also means refresh. A representative example is 'Sprite'. Blue goes well with any brand. This is also used by many companies because it expresses the image of professionalism, sincerity, and trust. It is often used by services that need to be based on trust, such as a bank or financial industry [2].

Color marketing is already being used in various fields, but more detailed research is needed for better efficiency in these days. Therefore, this study is to find what products, words, and feelings are associated with 6 colors (red, blue, green, yellow, white, and black) according to individual characteristics in this 
study. A survey was conducted by participants in their 20s and the results of this survey were analyzed using a decision tree. Also, we checked whether there were the differences by color depending on the favorite cellphone brand and the favorite car style. Building an advertisement strategy based on the cognitive differences in colors can have a positive impact on marketing.

\section{Related Works}

\subsection{Decision tree}

A decision tree is a flowchart-like tree structure, where each internal node represents a test on an attribute, each branch represents an outcome of a test, and class label is represented by each leaf node [3]. This is an analysis method to model by exploring relationships, patterns, and rules between the dependent variables and the independent variables [4]. Initial separation is based on the specific value of the independent variable that has the greatest influence on the dependent variable and separation is performed until no more separation is achieved. This method has the advantage of being easily understood and explained because it is represented by a tree structure. In particular, this technique can be used for any purpose like classification or prediction, and is more useful because it is easy to interpret [5]. It is an algorithm that finds the useful independent variables. It is also useful to find how independent variables influence the dependent variables through various interactions.

Decision tree analysis uses appropriate separation criteria and suspension rules according to the purpose and data structure. It also eliminates branches that have a high risk of increasing the classification error or have inappropriate reasoning rules [6]. As a tree structure can be visually represented, it is not only easy to interpret, but also it is easy to apply the model to new data. As it automatically finds interaction effects and nonlinearity, it is easy to see how two or more variables are combined to affect the dependent variables. It is also convenient because it is a nonparametric method that does not assume linearity, normality, or equal variance [7].

There are many researches on a decision tree. Beibei Guo's paper identified the causes that affect the dance teaching effect in colleges based on a data analysis and a decision tree model. An analysis model was used to find the influential causes, while an extensible decision tree was suggested and verified with examples using this. The research findings showed the theories of dance teaching in colleges, and provided an analysis model with great potential on applications [8]. In Guoying Zhang's study, a decision tree analysis was performed to look into the effects from working. The results showed that student age was the first major factor for better grade regardless of working status. Then, the factor of students' selfperception on the effect of working on academic performance mattered a lot. This analysis approach can be easily applied to other academic counseling to identify when working intensity can matter [9]. In Ilknur Karacan's paper, a decision tree was used to identify variables influencing life expectancy at birth. The data was collected from the databases of the World Bank, World Health Organization and World Life Expectancy. 9 of the 25 variables had the significant influences on life expectancy. Improving quality in these variables may result in increases in life expectancy and quality of life. Based on these, appropriate strategies can be developed to improve the quality and performance of health care systems by each country [10].

\subsection{Color marketing}

Color is an important factor that affects consumers' purchasing activities as it can influence on judgment, emotion, and psychological responses. Since color has a close influence on customers' desire, instinct, and unconsciousness, people respond to color. This can lead to more chance of purchasing products sometimes. According to the U.S. Color Research Institute, vision has $87 \%$ impact on product recognition and purchasing decision, and color also accounts for $60 \%$ of vision.

Marketing these days uses specific colors to convey information and images more intuitively to consumers who hate complex things and respond easily to images. For example, a certain color that breaks stereotypes can be used for younger people. Or, by using only one color that matches its product in the advertisement, the message can be effectively delivered by using the feeling from relationship between the advertisement and brand.

Color marketing began in 1920 with the red fountain pen of 'Parker' in the United States. Most fountain pens sold in the United States at that time were black or brown. 'Parker' had a great success by making the newly released fountain pen with the red color that women liked [11]. And in the mid-1950s, as colors evolved as central elements in planning products, it became known as color marketing. In a relatively short period of time, companies have produced products of various colors desired by consumers. Color 
marketing is now applied to all areas of consumer goods such as food, beverage, furniture, automobiles, and home appliances. In particular, the importance of color is prominent in high-tech IT devices including household appliances. In addition to white, various colors such as red, blue, and black are used in home appliances and intense colors are being introduced into portable digital devices. Previously, IT products such as cell phones, laptops, and digital cameras mainly used silver or gray to give a stylish and solid image.

There are diverse researches on color marketing. Nan Xiao and Fengjun Li's paper investigated and provided methods for effective design on international fashion color by international women's clothing brands. The purpose of this study is to find out the manner and methods of operation of fashion color in mature international women's clothing brands. It is important in the process of analyzing and extracting fashion colors to provide Chinese women's clothing brand color. It is used for processes starting from abstract color blocks to concrete store display of fashion color [12]. Shaip BYTYÇI's study showed a primary study using a survey. The purpose of this paper is to identify consumer awareness of the role and importance of color as a marketing tool in their decision-making process. This research investigated the observation of certain colors and their impact on the recipient's thoughts and emotions [13]. Mackenzie Bland's study was to search for the effects of color and color placement in the advertisement on purchase intent of loot box. It may contribute to research about color perception in marketing. More specifically, it established a link between color associations in Call-to-Action (CTA) buttons and online video game environments in which gambling takes place. The study tested the placement of color (foreground and background) and color itself (red, blue, and gray). The test showed that the color, red achieved the highest purchase intent for a theoretical loot box in an online video game scenario [14].

\section{Data collection and Method}

\subsection{Data collection}

The data used in this paper were collected through a survey of 55 participants in their 20 s mostly. It contains 28 variables of 10 independent variables and 18 dependent variables. The independent variables are gender, age, favorite fruit, favorite food, favorite subject, favorite color, favorite cellphone brand, favorite carrier, favorite car style, and favorite car brand. And the dependent variables are the associated product, the associated word, and the associated feeling of 6 colors (red, blue, green, yellow, white, and black) as in Table 1. Table 2 shows products, words, and feelings associated with each color.

Table1 Variables

Independent Variable Dependent Variable

- Gender

- Age

- Favorite fruit

- Favorite food

- Favorite subject

- Favorite color

- Favorite cellphone brand (LG, Samsung's

Galaxy, Apple's iPhone)

- Favorite carrier (LGU+, SKT, KT)

- Favorite car style (sedan, SUV, minivan, sports car)

- Favorite car brand

- The associated product of 6 colors (red, blue, green, yellow, white, and black)

- The associated word of 6 colors (red, blue, green, yellow, white, and black)

- The associated feeling of 6 colors (red, blue, green, yellow, white, and black)

Table2 List of the associated products, the associated words, and the associated feelings
The associated products
The associated words
The associated feelings 
cellphone, refrigerator, television, car, house, game, chicken, beer, orange juice, coffee, hamburger, clothes, clock variety, convenience, family, success, speed, tastiness, coolness, pride, fun, grace, child love, hate, happiness, unhappiness, pain, pleasure, sadness, passion, excitement, calmness

\subsection{Method}

Firstly, 18 decision trees from the analysis with each of 18 dependent variables were analyzed with 10 independent variables. 3 of them showed the significant results when the dependent variables were the associated feeling of blue, the associated word of yellow, and the associated feeling of yellow. Secondly, this study tried to find out the differences of the associated products, the associated words, and the associated feelings for the favorite cellphone brand (Samsung's Galaxy and Apple's iPhone) and the favorite car style (sedan and SUV) among the independent variables. This analysis was used to verify whether there were the differences in two brands and in two product types by color for the advertisement. This result can be used to the advertisement of brands and products.

\section{Research analysis and results}

\subsection{The results of decision trees}

\subsubsection{The associated feeling of blue}

The decision tree with the associated feeling of blue as the dependent variable is shown in Figure 1. The most important variable was gender. Most men felt 'calmness' about blue. On the other hand, most women felt 'sadness' as their emotion for blue. It is important to note that blue, as it usually means, can make men feel calm, but it can make women feel sad.

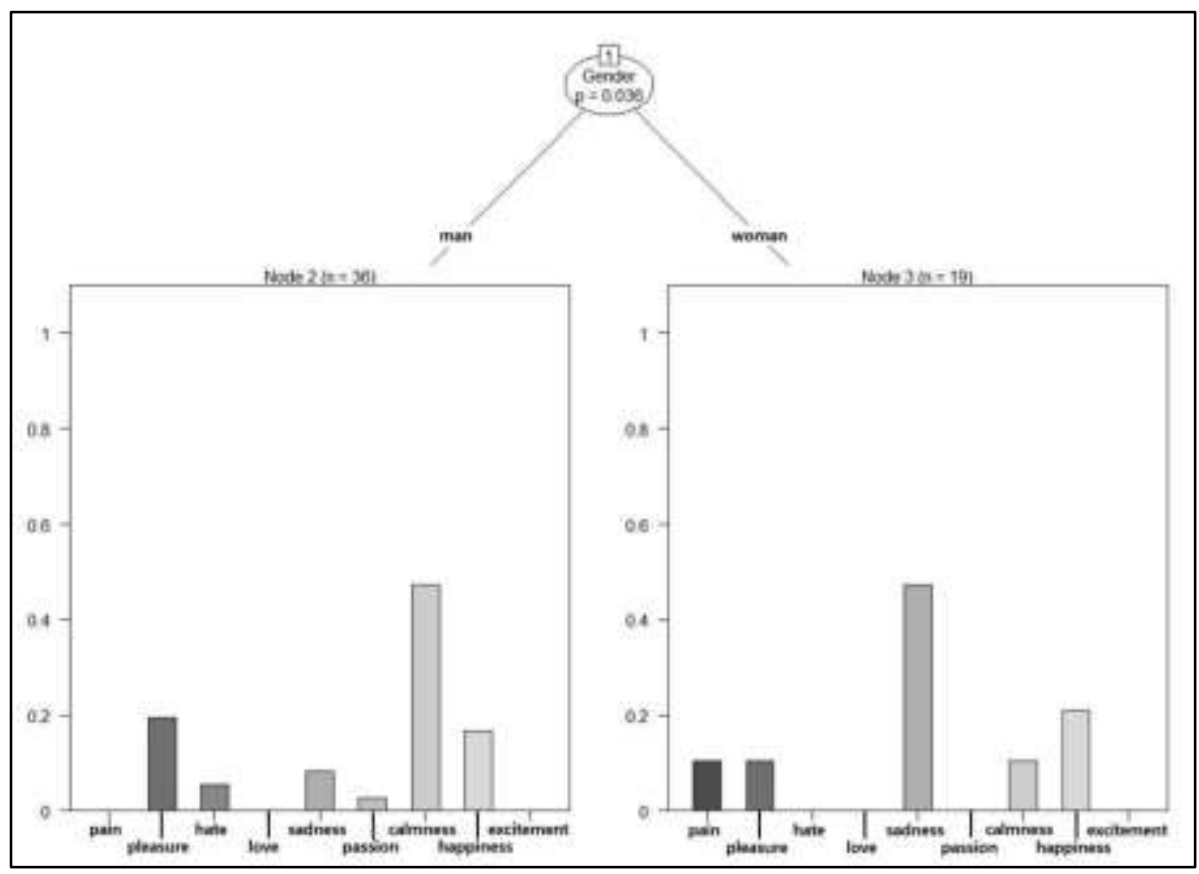

Figure 1 Decision tree of the associated feelings of blue

\subsubsection{The associated word of yellow}


Figure 2 shows the result of the decision tree with the associated word of yellow as the dependent variable. The most important variable in this one was color. People who liked red thought that yellow was related to 'family', 'variety', and 'fun'. On the other hand, people who liked black, green, and blue thought of 'child' for yellow, and people who liked yellow and white thought of 'fun' about yellow. As yellow is mainly used in children's products, words such as 'family', 'child', and 'fun' are associated with them.



Figure 2 Decision tree of the associated words of yellow

\subsubsection{The associated feeling of yellow}

The result of analysis of the decision tree with associated feelings of yellow as the dependent variable is shown in Figure 3. The most important variable was car. People who liked sedan or sports car felt 'happiness' for yellow. And people who liked SUV, minivan, or coupe felt 'pleasure' for yellow. Yellow is generally used to give a friendly and positive feeling, and this result also shows that it gives good feelings such as 'happiness' and 'pleasure'.



Figure 3 Decision tree of the associated feelings of yellow 


\subsection{Difference by color between brands and products}

\subsubsection{The associated product of Samsung and Apple}

Table 3 is a list of the associated products of Samsung's Galaxy and Apple's iPhone by color. Most words appear duplicated, but some words are different. The use of these set of words in the advertisement may be more interesting as it reflects consumers' perceptions of two brands. When using blue in the advertisement of Samsung's Galaxy and Apple's iPhone, 'cellphone' for Samsung's Galaxy and 'car' for Apple's iPhone are different. Therefor these words are good to use in the advertisement of each brand. It is also better to use 'clothes' and 'hamburger' for Samsung's Galaxy and 'game' and 'beer' for Apple's iPhone for green. And for yellow, it is better to use 'hamburger', 'game' for Samsung's Galaxy and 'clothes' and 'car' for Apple's iPhone. 'Car' for Samsung and 'clock' for Apple are different about white. These two words are good to use because they reflect the difference between the two brands. When using black, it is better to use 'clock' for Samsung's Galaxy and 'clothes' for Apple's iPhone.

Table3 The associated products of Samsung and Apple

\section{Samsung's Galaxy \\ Apple's iPhone}

Red car, hamburger, chicken, clothes, game

car, hamburger, clothes, chicken, game

Blue refrigerator, beer, car, cellphone, clothes

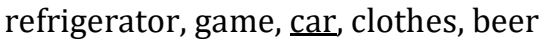

Green house, clothes, clock, television, hamburger $\quad$ house, game, beer, television, clock

Yellow chicken, orange juice, beer, hamburger, game orange juice, chicken, beer, clothes, $\underline{\text { car }}$

White refrigerator, clothes, house, cellphone, $\underline{\text { car }}$

refrigerator, clothes, cellphone, clock, house

Black coffee, television, cellphone, car, $\underline{\text { clock }}$

coffee, television, car, cellphone, $\underline{\text { clothes }}$

\subsubsection{The associated words of Samsung and Apple}

In comparing the associated words between Samsung's Galaxy and Apple's iPhone, the results show that red, blue, and green are all the same as you can see in Table 4. Words in yellow are the same, but 'convenience' in Samsung's Galaxy and 'variety' in Apple's iPhone are different. There is the difference like 'family' in Samsung's Galaxy and 'pride' in Apple's iPhone for white. The difference in black is 'speed' in Samsung's Galaxy and 'variety' in Apple's iPhone. From results on these analyses, Samsung's Galaxy would be good to associate 'convenience' in yellow, 'family' in white, and 'speed' in black. For Apple's iPhone, it is better to use 'variety' in yellow and black and 'pride' in white.

Table4 The associated words of Samsung and Apple

\section{Samsung's Galaxy}

Red speed, pride, tastiness, grace, success
Apple's iPhone

speed, pride, tastiness, success, grace 
Green family, convenience, coolness, child, variety

Yellow child, tastiness, fun, family, convenience

White grace, convenience, child, family, variety

Black pride, grace, convenience, success, speed family, convenience, child, coolness, variety

child, fun, variety, tastiness, family

grace, convenience, pride, child, variety

pride, grace, success, convenience, variety

\subsubsection{The associated feelings of sedan and SUV}

From the result of the associated feelings by color of sedan and SUV, you can see that most words are similar as in Table 5. The associated feeling words in green, yellow, and black are all the same. In the advertisement of sedan, red can give the positive feelings such as 'pleasure' and 'happiness', but in the SUV's advertisement, red can give the negative feelings like 'hate' and 'pain'. People who like sedan feel 'excitement' for blue, while ones like SUV feel 'hate'. The differences in white are 'pleasure' and 'pain' in sedan and 'sadness' and 'unhappiness' in SUV. Using the different words of the associated feeling between sedan and SUV in the advertisement is good to reflect features consumers think about products.

Table5 The associated feelings of sedan and SUV

sedan

Red passion, love, excitement, pleasure, $\underline{\text { happiness }}$ sadness, pleasure, calmness, happiness, excitement

Blue

Green calmness, happiness, pleasure, love, sadness

Yellow pleasure, happiness, excitement, hate, love

White calmness, happiness, pleasure, love, pain

Black
SUV

passion, love, excitement, $\underline{\text { hate, }}$ pain

calmness, sadness, happiness, pleasure, $\underline{\text { hate }}$

calmness, happiness, pleasure, sadness, love

pleasure, happiness, excitement, love, hate

calmness, $\quad \underline{\text { sadness, }} \quad$ happiness, unhappiness, love

calmness, unhappiness, pain, hate, sadness

\subsection{Network graph}

\subsubsection{Network graph of Samsung}

The network graph was used to find out the products, the words, and the feelings most related to Samsung. Figure 4 shows the network graph of the associated products, the associated words, and the associated feelings for each color of Samsung. In the Samsung's network graph, 'success', 'family', 'clothes', 
and 'happiness' are the most important. Based on this result, it will be nice if the image of a happy family or a successful person is used in the Samsung's Galaxy advertisement. AP means the associated products, AW means the associated words, and AF means the associated feelings in the picture.

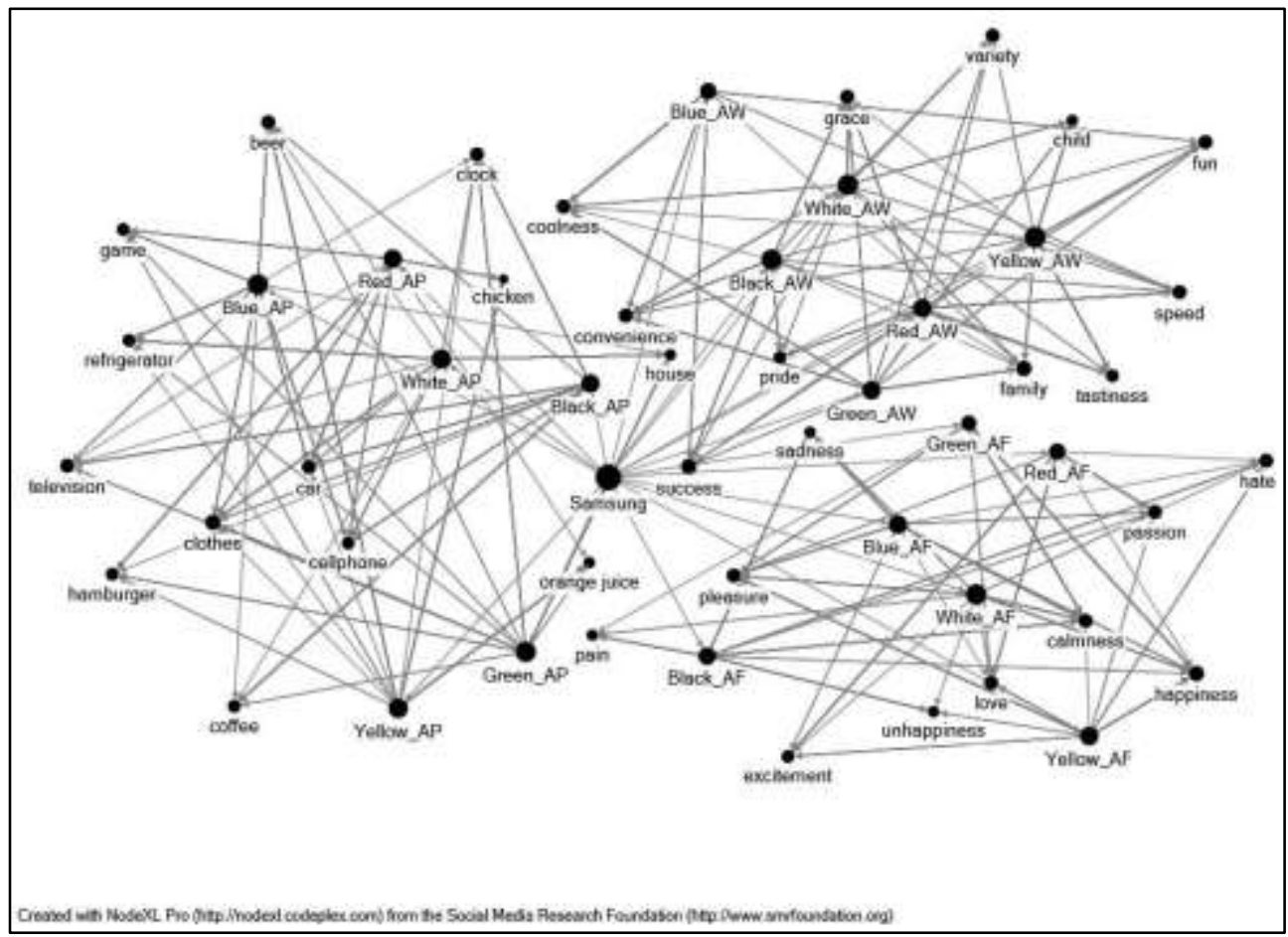

Figure 4 Network graph of Samsung

\subsubsection{Network graph of Apple}

The products, the words, and the feelings related to Apple can be seen in the network graph in Figure 5 . In Apple's network graph, 'car', 'clothes', 'coffee', 'child', 'speed', 'grace', 'variety', 'convenience', 'calmness', 'hate', and 'happiness' are important words. Apple's iPhone advertisement can use images such as a speedy car, an elegant coffee drinker, happy kids and convenience based on the result from the network analysis. AP means the associated products, AW means the associated words, and AF means the associated feelings. 


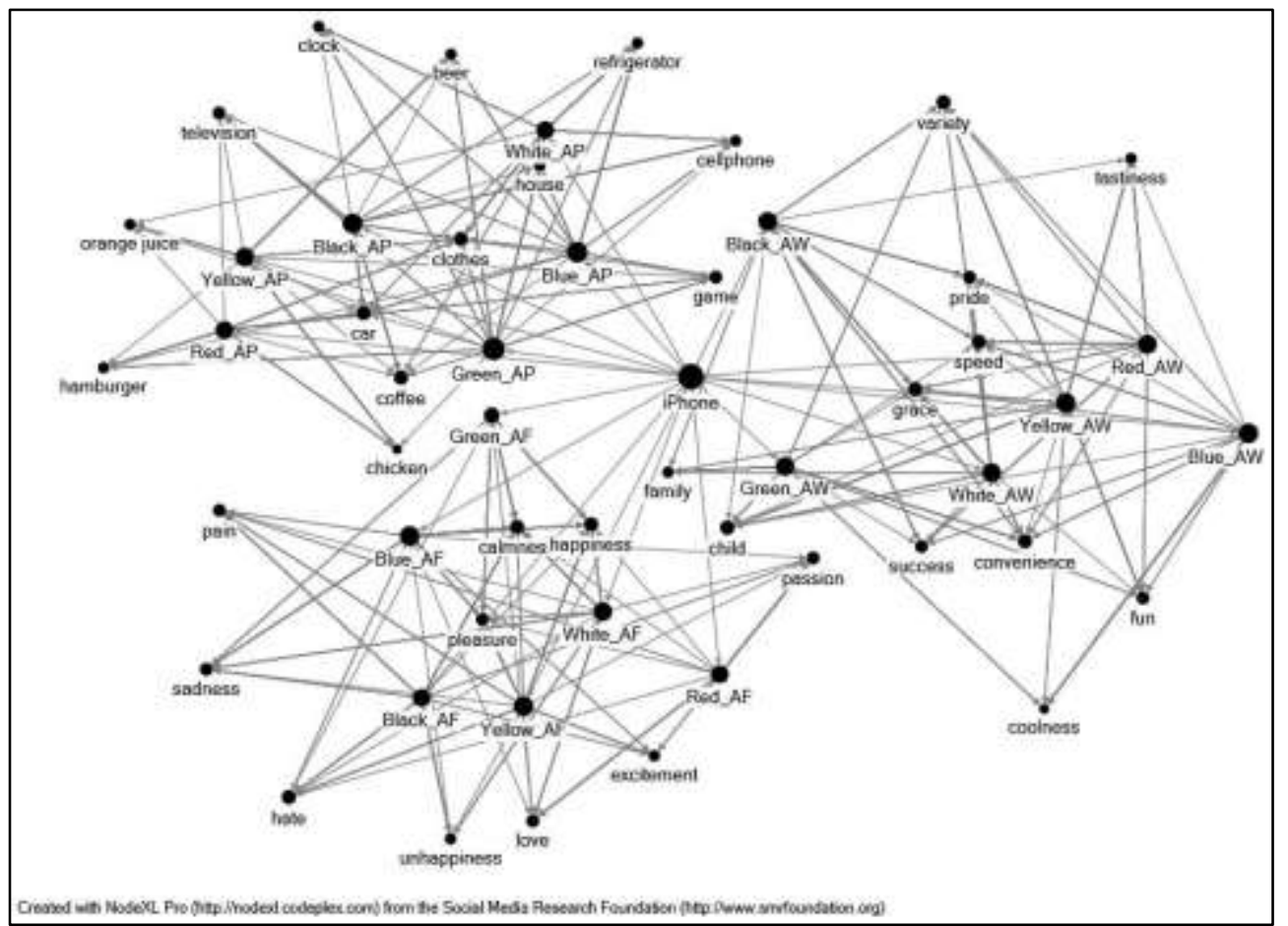

Figure 5 Network graph of Apple

\subsubsection{Network graph of sedan}

The sedan's network graph to investigate the most relevant products, words, and feelings is shown in Figure 6. Its most important words are 'clothes', 'success', and 'family'. In the advertisement of sedan using the most important words in this network graph, it's good to use the image of a suited person that seems to be successful with his or her family. In this graph, AP means the associated products, AW means the associated words, and $\mathrm{AF}$ means the associated feelings.

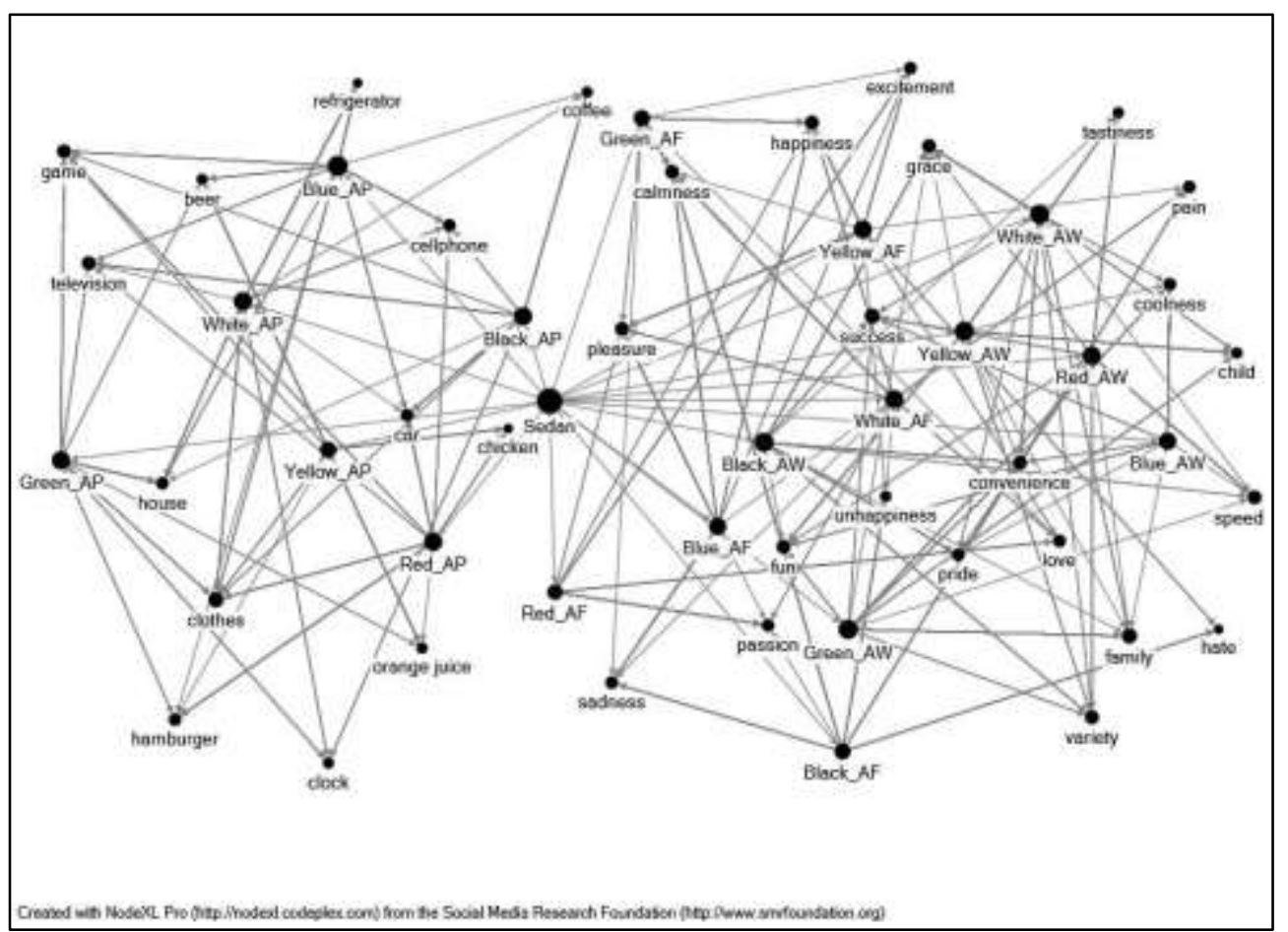

Figure 6 Network graph of sedan 


\subsubsection{Network graph of SUV}

Figure 7 shows the products, the words, and the feelings most related to SUV. In the SUV's network graph, 'clothes', 'coffee', 'child', 'convenience', 'variety', 'calmness', and 'pain' are the most significant related words. In the advertisement of SUV based on the network analysis, it is good to emphasize the convenience and calmness of SUV when carrying a child in this car. AP means the associated products, AW means the associated words, and AF means the associated feelings.

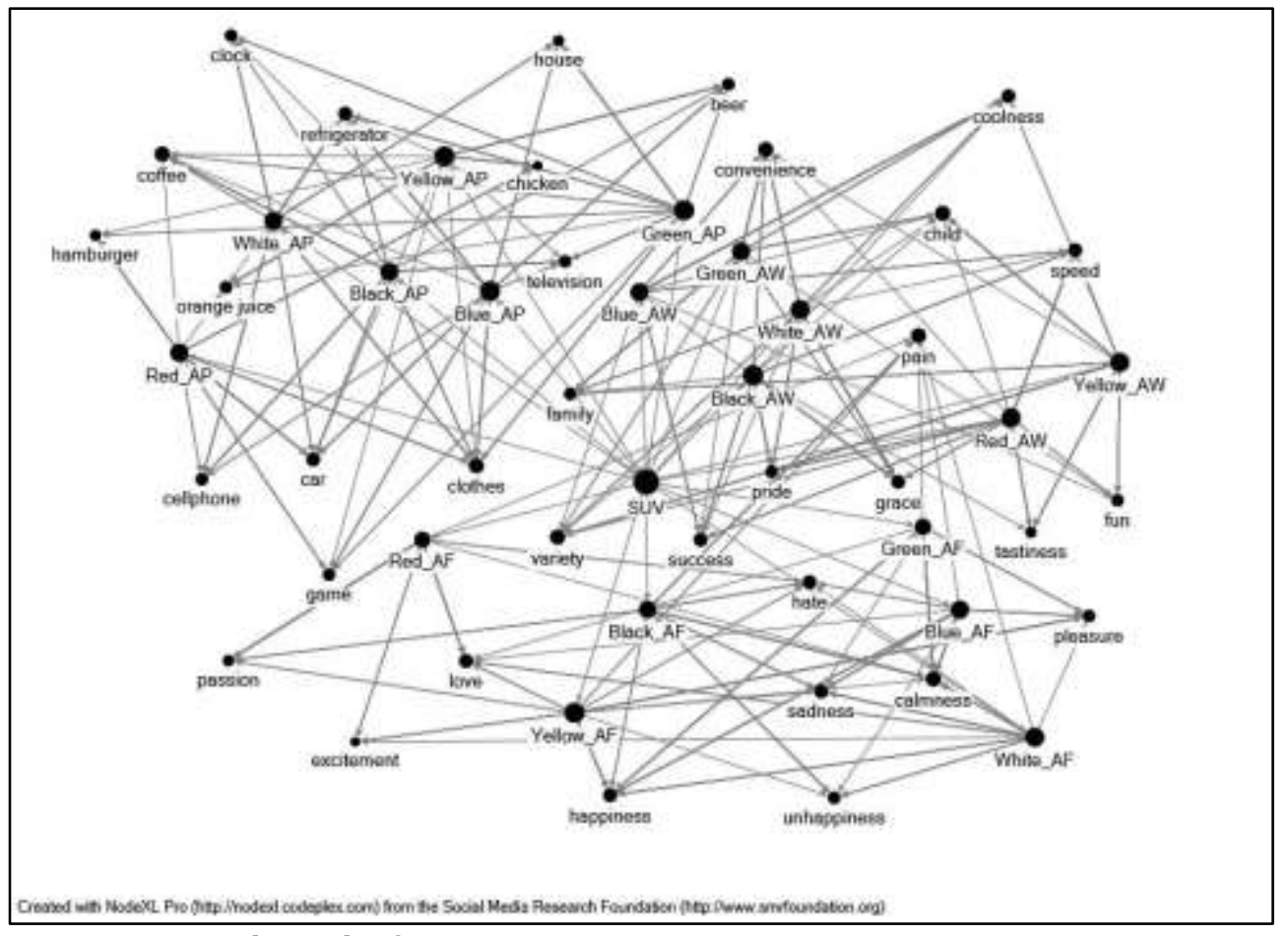

Figure 7 Network graph of SUV

\section{Conclusions}

In this study, we tried to find out if there were the differences in the products, the words, and the feelings related to each color by company brands and products. For this analysis, gender, age, favorite fruit, favorite food, favorite subject, favorite color, favorite cellphone brand, favorite carrier, favorite car style, and favorite car brand were used as the independent variables representing individual characteristics. In addition, the associated products, the associated words, and the associated feelings of 6 colors (red, blue, green, yellow, white, and black) were used the dependent variables.

Firstly, the results of the decision tree analysis are as follows. When the dependent variables were the associated feelings of blue, the associated words of yellow, and the associated feelings of yellow, significant results were obtained. Firstly, most men felt 'calmness' and most women felt 'sadness' for blue. Secondly, people who liked red thought that yellow was related to 'family', 'variety', and 'fun'. People who liked black, green, or blue thought of 'child', and ones who liked yellow or white thought of 'fun' about yellow. Thirdly, people who liked sedan or sports car felt 'happiness' for yellow, and ones who liked SUV, minivan, or coupe felt 'pleasure' for yellow.

Secondly, this study analyzed to see if there were any differences in the associated products, the associated words, and the associated feelings of two brands (Samsung's Galaxy and Apple's iPhone) and two products (sedan and SUV) regarding color cognition. Most showed similar results, but there were the differences of one or two words for each color. In the advertisement of two brands (Samsung's Galaxy and Apple's iPhone) and two products (sedan and SUV), the difference of the associated products, the associated words, and the associated feelings can be used to have a more positive impact on the products because that's the difference consumers think about brands or products.

Thirdly, the results of the associated products, the associated words, and the associated feelings of 6 colors of Samsung, Apple, sedan, and SUV were visualized as the network graphs. In the Samsung's network analysis graph, 'success', 'family', 'clothes', and 'happiness' were identified as important. The Apple's network graph showed that 'car', 'clothes', 'coffee', 'child', 'speed', 'grace', 'variety', 'convenience', 
'calmness', 'hate', and 'happiness' were the most important words. The most related words in the sedan's network graph were 'clothes', 'success', and 'family'. Lastly, 'clothes', 'coffee', 'child', 'convenience', 'variety', 'calmness', and 'pain' were the most significant in the SUV's network graph.

Because what people think about a certain brand or product is different, it is difficult to know whether a particular color will have good or bad effect. Therefore, applying the approach suggested in this study to the advertisements makes it possible to reflect consumers' cognition on brands and products in advertisements

This study has the following limitations. The questionnaire was targeted to young participants in their $20 \mathrm{~s}$, and the number of respondents is 55 . Therefore, future research better includes participants with age groups with more diverse ages. It is also better to increase the size of samples, the number of respondents to the survey. Only 6 representative colors (red, blue, green, yellow, white, and black) were used in this study. It is expected that more detailed and diverse analysis results can be obtained by adding more various colors.

\section{References}

[1] Alt M. Emotional responses to color associated with an advertisement[doctoral dissertation]. Bowling Green State University; 2008.

[2] Singh S. Impact of color on marketing. Management Decision. 2006.

[3] Sharma H, Kumar S. A survey on decision tree algorithms of classification in data mining. International Journal of Science and Research(IJSR). 2016;5(4):2094-2097.

[4] Quinlan JR. Induction of decision trees. Machine learning. 1986;1(1):81-106.

[5] Baik S, Bala J. A decision tree algorithm for distributed data mining: Towards network intrusion detection. In International Conference on Computational Science and Its Applications. Berlin: Springer; 2004. p. 206-212.

[6] Chandra B, Kothari R, Paul P. A new node splitting measure for decision tree construction. Pattern Recognition. 2010;43(8):2725-2731.

[7] Chen FH, Chi DJ, Wang YC. Detecting biotechnology industry's earnings management using Bayesian network, principal component analysis, back propagation neural network, and decision tree. Economic Modelling. 2015;46:1-10.

[8] Guo B. Analysis on Influencing Factors of Dance Teaching Effect in Colleges Based on Data Analysis and Decision Tree Model. International Journal of Emerging Technologies in Learning (iJET). 2020;15(9):245-257.

[9] Zhang G, Shao CY, Johnston CR. Working Students and Their Academic Performance-A Decision Tree Analysis. Journal of Higher Education Theory and Practice. 2019;19(7).

[10] Karacan I, Sennaroglu B, Vayvay O. Analysis of life expectancy across countries using a decision tree. Eastern Mediterranean Health Journal. 2020;26(2):143-151.

[11] Kim JH, Lim SA, Choi HH. Promotional Video Production which fused The Motion Graphics and Color Marketing. Life Science Journal. 2014;11(7s).

[12] Xiao N, Li F. Extraction and Analysis of Fashion Color in Women's Clothing Brand. In 4th International Conference on Culture, Education and Economic Development of Modern Society (ICCESE 2020). Atlantis Press; 2020. p. 252-257.

[13] BYTYÇI S. Influence of Colors as a Key Element in Consumer Marketing. Expert Journal of Marketing. $2020 ; 8(1)$

[14] Bland M. Color and Color Placement Effects on Purchase Intent of Loot Boxes in Video Games[dissertation]. University of Central Florida; 2020. 